\title{
Roberto Mange, a criação do Centro Ferroviário de Ensino e Seleção Profissional (CFESP) e a formação para o trabalho nas décadas de 1930 e 1940
}

\author{
Roberto Mange, the creation of the Railroad Center for Professional Education and Selection \\ (CFESP) and training for work in the 1930s and 1940s
}

Roberto Mange, la creación del Centro Ferroviario de Educación y Selección Profesional (CFESP) y

formación para el trabajo en las décadas de 1930 y 1940

Recebido: 02/10/2021 | Revisado: 07/10/2021 | Aceito: 08/10/2021 | Publicado: 10/10/2021

Sandra Maria de Assis
ORCID: https://orcid.org/0000-0002-9577-9656
Knstituto Federal de Educação, Ciência e Tecnologia do Rio Grande do Norte, Brasil
E-mail: acgeml @ hotmail.com
Karoline Louise Silva da Costa
ORCID: https://orcid.org/0000-0002-7157-1121
E-mail: Karolinepedagoga @gmail.com
Olívia Morais de Medeiros Neta
Instituto Federal de Educação, Ciência e Tecnologia do Rio Grande do Norte, Brasil
ORCID: https://orcid.org/0000-0002-4217-2914
Instituto Federal de Educação, Ciência e Tecnologia do Rio Grande do Norte, Brasil
E-mail: olivianeta@gmail.com

\begin{abstract}
Resumo
O objetivo deste artigo é explicitar as articulações que envolveram Roberto Mange e a criação e funcionamento do Centro Ferroviário de Ensino e Seleção Profissional (CFESP), criado em 1934, para formar e selecionar ferroviários. A pesquisa insere-se no campo da História da Educação Profissional e justifica-se pela importância do CFESP para qualificação e racionalidade da formação dos operários das ferrovias, além de ter originado outros Centros Ferroviários de Ensino e Seleção Profissional no Brasil. A metodologia utilizada foi a pesquisa documental e bibliográfica através de autores como Zanetti (2001), Fonseca (1961); Cunha (2000), Pedrosa (2014), Ciavatta (2009), dissertações e teses. A trajetória profissional de Roberto Mange relaciona-se com a criação, em 1923, do curso de Mecânica Prática do Liceu de Artes e Ofícios de São Paulo; com criação da Escola Profissional Mecânica, em 1924; com a criação do Curso de Ferroviários de Serviço de Ensino e Seleção Profissional da Sorocabana e criação do Instituto de Organização Racional do Trabalho (IDORT), ambos em 1931; e finalmente, a criação do CFESP destinado à formação de trabalhadores para as ferrovias em São Paulo e outros estados brasileiros. Concluímos que a análise apresentou elementos que corroboram a argumentação sobre o papel do engenheiro Mange nas ações relacionadas à racionalização do trabalho e aplicação dos métodos de gestão científica, favorecendo a cooperação entre as estradas de ferro e os poderes públicos.
\end{abstract}

Palavras-chave: Roberto Mange; CFESP; Intelectual da educação; Ensino técnico profissional.

\begin{abstract}
The objective of this article is to explain the articulations that involved Roberto Mange and the creation and functioning of the Railway Center for Professional Education and Selection (CFESP), created in 1934, to train and select railway workers. The research is part of the field of the History of Professional Education and is justified by the importance of CFESP for the qualification and rationality of the training of railway workers, in addition to having originated other Railway Education and Professional Selection Centers in Brazil. The methodology used was documentary and bibliographic research through authors such as Zanetti (2001), Fonseca (1961); Cunha (2000), Pedrosa (2014), Ciavatta (2009), dissertations and theses. Roberto Mange's professional trajectory is related to the creation, in 1923, of the Practical Mechanics course at the School of Arts and Crafts of São Paulo; with the creation of the Escola Profissional Mecânica, in 1924; with the creation of the Sorocabana Teaching Service and Professional Selection Railway Course and the creation of the Rational Work Organization Institute (IDORT), both in 1931; and finally, the creation of the CFESP aimed at training railway workers in São Paulo and other Brazilian states. We conclude that the analysis presented elements that corroborate the argumentation about the role of engineer Mange in actions related to the rationalization of work and application of scientific management methods, favoring cooperation between the railways and public authorities.
\end{abstract}

Keywords: Roberto Mange; CFESP; Education intellectual; Professional technical education. 


\begin{abstract}
Resumen
El objetivo de este artículo es explicar las articulaciones que involucraron a Roberto Mange y la creación y funcionamiento del Centro Ferroviario de Formación y Selección Profesional (CFESP), creado en 1934, para la formación y selección de trabajadores ferroviarios. La investigación es parte del campo de la Historia de la Educación Profesional y se justifica por la importancia de la CFESP para la calificación y racionalidad de la formación de los trabajadores ferroviarios, además de haber originado otros Centros de Educación y Selección Profesional Ferroviaria en Brasil. La metodología utilizada fue la investigación documental y bibliográfica a través de autores como Zanetti (2001), Fonseca (1961); Cunha (2000), Pedrosa (2014), Ciavatta (2009), disertaciones y tesis. La trayectoria profesional de Roberto Mange está relacionada con la creación, en 1923, del curso de Mecánica Práctica en la Escuela de Artes y Oficios de São Paulo; con la creación de la Escola Profissional Mecânica, en 1924; con la creación del Servicio Docente de Sorocabana y Curso Ferroviario de Selección Profesional y la creación del Instituto de Organización Racional del Trabajo (IDORT), ambos en 1931; y finalmente, la creación de la CFESP destinada a la formación de trabajadores ferroviarios en São Paulo y otros estados brasileños. Concluimos que el análisis presentó elementos que corroboran la argumentación sobre el papel del ingeniero Mange en acciones relacionadas con la racionalización del trabajo y la aplicación de métodos de gestión científica, favoreciendo la cooperación entre los ferrocarriles y las autoridades públicas.
\end{abstract}

Palabras clave: Roberto Mange; CFESP; Educación intelectual; Educación técnica profesional.

\title{
1. Introdução
}

A criação do Centro Ferroviário de Ensino e Seleção Profissional (CFESP) deu-se através do Decreto Estadual do Estado de São Paulo, nº 6537, de 04 de julho de 1934, com a finalidade de formar e selecionar trabalhadores para a estrada de ferro Sorocabana. Sua criação coube ao engenheiro suíço Roberto Mange, professor da Politécnica e um personagem importante na constituição do ensino técnico industrial no Brasil.

Nesse sentido, o objetivo desse artigo é explicitar as articulações que envolveram Roberto Mange e a criação e o funcionamento do CFESP no contexto das transformações socioeconômicas que o Brasil vivenciava e que impulsionaram a do Ensino Técnico Profissional nas décadas de 1930 e 1940.

A pesquisa insere-se no campo da História da Educação Profissional e justifica-se pela importância do CFESP para qualificação e racionalidade da formação dos operários das ferrovias, além de ter originado outros Centros Ferroviários de Ensino e Seleção Profissional no Brasil. Dessa forma, a primeira parte do texto apresenta o engenheiro e intelectual da educação Roberto Mange como professor da Politécnica de São Paulo e sua inserção nas Ferrovias Paulistas bem como as articulações para a criação do CFESP; e a segunda parte discute o protagonismo dos CFESPs na formação de trabalhadores para as ferrovias em São Paulo e sua expansão para outros estados brasileiros.

\section{Metodologia}

A base teórica deste texto resulta de pesquisa bibliográfica e documental realizada conforme registros disponíveis em livros, artigos e teses publicadas e decorrentes de pesquisas realizadas anteriormente e cujo conteúdo contribuiu para a maior parte da escrita. O percurso metodológico baseou-se em Severino (2016), para quem a abordagem e o tratamento do objeto da pesquisa deve ser conduzido conforme a leitura e análise de todas as fontes documentais, disponíveis para a obtenção das categorias de análises. Na tessitura desse artigo, recorremos também ao auxílio da pesquisa com documentos, especialmente de fotografias e notícias de jornais já analisadas pelos autores consultados, mas que serviram para corroborar com o aporte teórico.

A pesquisa bibliográfica utilizou-se de autores, como: Zanetti (2001), Fonseca (1961); Cunha (2000), Pedrosa (2014), Ciavatta (2009), bem como algumas dissertações e teses. No intuito de evitar o alongamento, favorecer a fluidez, e considerando-se os dados coletados, registrados e sistematizados por fim analisados, o texto estrutura-se em duas partes: a primeira parte trata da trajetória acadêmica e profissional de Roberto Mange, a partir da criação do curso de Mecânica Prática do Liceu de Artes e Ofícios de São Paulo (1923), passando pela criação da Escola Profissional Mecânica, em 1924 e por uma 
viagem à Europa, em 1930, para aperfeiçoamento sobre a formação da mão de obra das ferrovias alemãs; a segunda trata da criação do Curso de Ferroviários de Serviço de Ensino e Seleção Profissional da Sorocabana, e do IDORT (Instituto de Organização Racional do Trabalho), ambos em 1931 e, finalmente, a criação do CFESP.

\section{Roberto Mange nos Trilhos das Ferrovias}

Roberto Auguste Edmond Mange, nasceu em 31 de dezembro de 1885 natural de La Tour de Peilz, Cantão de Vaud na Suíça. Em 1939, naturalizado brasileiro, passou a se chamar Roberto Mange. Na primeira infância - devido ao trabalho do seu genitor Jules Louis Mange, representante comercial de uma fábrica de relógios, mudou-se com a família para viver em Lisboa, onde aprenderia a falar a língua portuguesa e completaria os estudos na Escola Primária. ${ }^{1}$

Prosseguiu os estudos na cidade de Minden, na Alemanha, retornando a Suíça em 1904, para cursar engenharia mecânica na Eidgenosseche Technische Hochschule, de Zurique. Outrora, essa escola fora o Instituto Polytechnikim, fundado em 1850. Formou-se engenheiro mecânico em 1910, sendo contratado para trabalhar na empresa Brown - Boveri, na cidade de Baden.

Chegou ao Brasil, em 1913, a convite do brasileiro Antônio de Paula Souza, então diretor da Politécnica de São Paulo e ex-aluno da Politécnica de Zurique. Paula Souza convidara dois engenheiros suíços para lecionarem disciplinas vinculadas ao estudo da engenharia em nível universitário na Politécnica de São Paulo, um dos berços do pensamento industrial brasileiro. Contratado para lecionar Engenharia Mecânica Aplicada às Máquinas, começaria ali o envolvimento de Mange com as ferrovias de São Paulo.

Devido a Primeira Guerra que começara na Europa, retornou à Suíça no ano seguinte, para servir, por um ano, na Guarda Municipal Suíça. Voltou ao Brasil, em 1915, indo viver na cidade de Ribeirão Pires, onde permaneceu até o ano de 1922. Em 1923, com subvenção federal, fundou o Curso de Mecânica Prática com o objetivo de formar mecânicos e ajustadores. Na condição de professor da Politécnica de São Paulo, Mange foi o responsável pela superintendência do curso que funcionou como um anexo ao Liceu de Artes e Ofícios de São Paulo e ali teria iniciado o experimento com as séries metódicas nas oficinas, como recurso indispensável para assegurar a preparação profissional adequada dos alunos.

De acordo com Zanetti (2001), havia o apoio de algumas empresas ferroviárias, que enviavam jovens alunos para se matricular na Escola Profissional Mecânica, assegurando uma boa formação para os trabalhadores das estradas. No entanto, por falta dos recursos da subvenção estatal, o curso só funcionou naquele ano. Com a implantação da Escola Profissional Mecânica, em $1924^{2}$, deu-se a introdução das séries metódicas da aprendizagem destinadas a disciplinar e formar o caráter dos jovens aprendizes, além de dotá-los da qualificação que as empresas ferroviárias exigiam de seus quadros.

\footnotetext{
${ }^{1}$ C.f Senai. De Homens e Máquinas. São Paulo, SENAI, 1991, p. 35.

${ }^{2}$ C.f. Pedrosa (2014), Mange dirigiu a Escola Profissional Mecânica até o ano de 1928 e sob sua supervisão, um grupo de estudiosos, introduziu as séries metódicas no Brasil.
} 
Figura 1: Mange, em 1927, na Escola Profissional Mecânica.

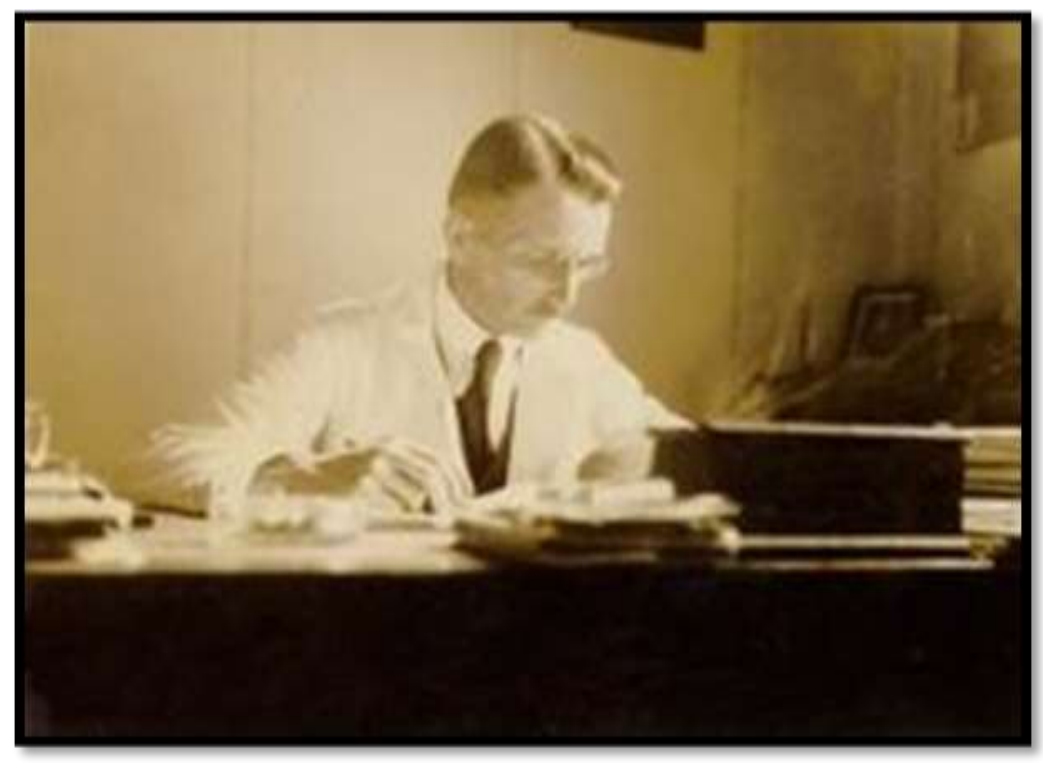

Fonte: https://pt.wiki9p92edia.org/wiki/Roberto_Mange.

Voltou à Europa, em 1929, quando realizou viagem à Alemanha, para estudar o processo de aprendizagem dos operários das ferrovias desse país, aperfeiçoando-se para aplicar os conhecimentos adquiridos nessa experiência que, posteriormente, orientou nas companhias de estradas de ferro de São Paulo, conforme os procedimentos desenvolvidos nas estradas de ferro alemãs. Segundo Zanetti (2001, p. 55), no Laboratório de Psicotécnica das Estradas de Ferro, Mange reuniu documentação e conhecimentos que seriam transmitidos e utilizados, posteriormente, nas empresas ferroviárias do Brasil.

No retorno, o professor Mange, trouxe projetos e ofereceu-os para implantar na Cia Paulista de Estradas de Ferro e na Central do Brasil, o que não foi possível àquele momento. Somente em 1931, com a criação do Curso de Ferroviários do Serviço de Ensino e Seleção Profissional da Sorocabana ${ }^{3}$, ele pôde, enfim, pôr em prática o que planejara desde 1924 . O curso mostrou “a economia e a eficiência dos métodos racionais da seleção profissional, graças às tabelas e gráficos elaborados [...] pelo engenheiro Mange" (Bologna, 1942 apud Zanetti, 2001, p. 08).

A criação do Instituto de Organização Racional do Trabalho (IDORT), em 1931, da qual foi um dos protagonistas ${ }^{4}$, consolidou as ações no sentido da racionalização do trabalho e aplicação dos métodos de gestão científica, favorecendo a cooperação entre as estradas de ferro e os poderes públicos.

Na sequência, criou o Centro Ferroviário de Ensino e Seleção Profissional (CFESP), através do Decreto Estadual $n^{\circ}$ 6537 de 04 de julho de $1934^{5}$ e o dirigiu por um tempo. O referido centro seria responsável por formar e selecionar trabalhadores para as ferrovias. Zanetti (2001), afirma que, em função de seus resultados positivos, outras estradas de ferro (públicas e privadas aderiram ao projeto e novos cursos, nos moldes dos que funcionavam no CFESP foram criados em outras regiões do país.

Nesse contexto, o engenheiro Mange, que já transitava com desenvoltura no governo paulista, passando a articular ações relacionadas ao ensino profissional também no governo federal, onde evidencia-se que

\footnotetext{
${ }^{3}$ Consulte-se Pedrosa (2014).

${ }^{4}$ A criação do IDORT contou com o empenho de um grupo de homens de projeção, vinculados ao ensino profissionalizante do qual faziam parte, além de Roberto Mange, Armando Salles de Oliveira, Gaspar Ricardo Jr, Geraldo de Paula Souza, Aldo Mário Azevêdo e Lourenço Filho. C.f. Zanetti (2001, p. 56).

${ }^{5}$ Diário Oficial, 13/07/1934, p.1. Disponível em: http://dobuscadireta.imprensaoficial.com.br/. Acesso em: 28 de julho de 2021.
} 
Em 1937, mesmo ano em que Getúlio Vargas anunciou o Estado Novo, Mange foi nomeado supervisor do gabinete de psicotécnica, anexo à Escola Técnica Getúlio Vargas. Em todas essas ações, Mange já estava criando as bases do novo ensino industrial brasileiro, isto é, estava envolvido com a instituição de um ensino industrial articulado a um processo de crescimento industrial (Pedrosa, 2014, p. 51).

O processo de constituição do ensino industrial brasileiro, já em andamento a partir de 1934, seria marcado por pressões e disputas, especialmente a que colocava em lados opostos o Ministro da Educação Gustavo Capanema que defendia a vinculação do ensino profissional ao sistema regular de ensino, sob o controle do seu ministério e os empresários industriais articulados por Euvaldo Lodi e Roberto Simonsen, vinculados ao Ministério do Trabalho chefiado por Waldemar Falcão. Nesse cenário, Mange dialogava com ambos os grupos. Sua presença

[...] na constituição do novo ensino industrial ocorreu desde o primeiro momento em 1934, quando Capanema criou a Comissão Organizadora do Plano de Ensino Profissional. [...] atuou na comissão criada pelo ministro Capanema em 1941 para elaborar as diretrizes do ensino industrial e que concluiu, em fins de 1941, o anteprojeto de Lei Orgânica do Ensino Industrial. A Comissão era formada por Gustavo Capanema (presidente), Horácio da Silveira, Lourenço Filho, Leon Renault, Francisco Montojos e Rodolfo Fuchs. Mange e integrantes das Forças Armadas atuaram como assessores da comissão. [...] fez parte de outras comissões, além de ter sido convidado diversas vezes pelo MES para auxiliar também na organização do sistema de ensino técnico (Pedrosa, 2014, p. 51).

Havia urgência para se pensar e materializar soluções viáveis para o problema da carência de mão de obra qualificada para suprir a necessidade surgida com a Segunda Guerra e o surto de industrialização do país. O exemplo do CFESP atraíra a atenção para Roberto Mange, daí as indicações/convites/convocações para participar de várias comissões, entre elas a Comissão Interministerial, da qual participou como consultor técnico assessorando Euvaldo Lodi e Roberto Simonsen.

A proposta que construiu juntamente com Luderitz e Faria Góes Filho, depois de discutida e acrescida de pequenas alterações, resultaria no Decreto que criou o $\mathrm{SENAI}^{6}$, do qual seria diretor regional em São Paulo, cargo que ocupou até sua morte, em 1955.

As viagens de emissários do governo ao exterior, especialmente do Ministério da Educação, para visitas, estudos, contratações de técnicos, participação em congressos, conferências e outros eventos já tinham sido incorporadas à dinâmica da constituição do ensino industrial. Nesse sentido, Roberto Mange faria duas viagens importantes, entre os anos de 1940 e 1942 , para a Europa e Estados Unidos, das quais resultaram a contratação de professores e técnicos para atuarem na Escola Técnica Nacional, antes chamada de Liceu Industrial.

A respeito das contratações dos 42 professores suíços, o Jornal Diário de Notícias ${ }^{7}$ do dia 24 de janeiro de 1942 , informava que 26 deles já se encontravam no Brasil e teriam participado de uma reunião onde foram informados que fariam um curso breve de adaptação. Todos lecionariam, inicialmente, no Liceu Industrial do Distrito Federal que, por sua localização e instalações. seria ponto de irradiação do ensino profissional no país. A posteriori, os professores suíços lecionariam periodicamente em outros estabelecimentos nos quais o governo tencionava abrir cursos de aperfeiçoamento para capacitar os professores brasileiros que atuariam no ensino profissional.

Como primeiro Diretor regional do SENAI teve uma atuação bastante produtiva por 13 anos deixando um legado de 27 escolas SENAI em funcionamento, o que lhe valeu o título de “o semeador de escolas”, já reportado nesse texto. A 6a região abrangia, além de São Paulo, Mato Grosso, Goiás e o território de Guaporé (hoje Rondônia).

O SENAI de São Paulo era referência nacional e no papel de gestor do departamento regional mais importante, Roberto Mange “elaborava valores e estratégias para o ensino industrial, introduzia inovações e transformava-as em padrões

\footnotetext{
${ }^{6}$ Decreto Federal no 4048 de 22 de janeiro de 1942.

${ }^{7}$ http://memoria.bn.br/DocReader/DocReader.aspx $?$ bib $=093718 \_02 \&$ pesq=\%22Francisco\%20Montojos $\% 22 \& p a s t a=a n o \% 20194 \& p a g f i s=85$ 89
} 
pedagógicos e, principalmente, fazia tudo isso ser difundido pelos demais departamentos regionais" (Pedrosa, 2014, p. 53). Para difundir tais valores recorria as conferências que proferia para outros diretores regionais ${ }^{8}$.

Implantou no SENAI o Serviço de Seleção e Orientação Profissional denotando seu apreço pela Psicologia como ferramenta de auxílio na identificação de aptidões profissionais na seleção de trabalhadores. Para Miranda (2019), o apreço de Mange pela psicologia abriu caminhos para o desenvolvimento da Psicologia do Trabalho no Brasil, formando profissionais, estimulando a criação de serviços de Psicologia nas e empresas promovendo novos campos de atuação para os psicólogos. Não só colaborou com a criação da Academia Paulista de Psicologia como também foi seu primeiro presidente e patrono.

Pode-se dizer que a experiência do trabalho na Escola Profissional Mecânica do Liceu de Artes e Ofícios, no Serviço de Ensino e Seleção Profissional da Estrada de Ferro Sorocabana e no Centro de Ensino e Seleção Profissional (CFESP), serviu de referência inicial, uma vez que já lidava com a psicotécnica e com as séries metódicas de ensino, duas ferramentas importantes para a massificação do ensino industrial, que o SENAI se propunha a oferecer (Pedrosa, 2014).

Especialmente nas décadas de 1930 e 1940, período em que se assentaram as bases do ensino técnico industrial, o engenheiro, educador e intelectual Roberto Mange participou, praticamente, de todas as decisões, seja em nível público ou privado, seja como consultor técnico ou como gestor ou professor, e fez parte das principais instituições do industrialismo brasileiro e das decisões que estas demandaram.

Segundo Pedrosa (2014), ele não era um articulador político, mas transitava bem em todas as esferas de decisões públicas ou privadas. Tinha boas relações e vínculos com a maioria dos intelectuais, políticos e industriais brasileiros. Desenvolveu boas relações com os intelectuais escolanovistas e com o círculo de industrialistas devido seu trânsito tanto na Politécnica de São Paulo como na Confederação Nacional da Indústria (CNI) e no IDORT, além de circular no Ministério de Educação e Saúde Pública (MESP) e no Ministério de Indústria e Comércio (MTIC). Isso tudo denota sua influência tanto na esfera pública quanto na esfera privada, atestando sua competência técnica e favorecendo a compreensão de certos aspectos da contribuição de Roberto Mange para a História da Educação Profissional no Brasil.

O CFESP deu origem a outros Centros Ferroviários de Ensino e Seleção Profissional que se tornaram escolas técnicas criadas por diversas companhias férreas do estado de São Paulo, voltadas para a formação de jovens ferroviários. A primeira das empresas ferroviárias a aderir a esse processo foi a Sorocabana quando passou a enviar seus jovens aprendizes para a Escola Mecânica que funcionava anexa ao Liceu de Artes e Ofícios de São Paulo. Mais tarde, a mesma empresa criaria o seu próprio curso de ferroviários na Escola Profissional de Sorocaba, em 1931.

No contexto em que se insere a criação Curso de Ferroviários do Serviço de Ensino e Seleção Profissional da Sorocabana, havia a exigência de mão de obra especializada, o que significava investir na educação profissional, mas com estruturas definidas pela divisão social entre o trabalho manual e o trabalho intelectual. Destinados à formação de jovens, os cursos definiam formas e conteúdo de acordo com as necessidades de reprodução, e controle socioeconômico abrindo espaços de conhecimento e de possibilidades reais de trabalho e desenvolvimento pessoal. A direção da Estrada de Ferro Sorocabana, ter tinha consciência da sua indiscutível necessidade de pessoal preparado para os diversos setores das oficinas.

A aprendizagem tradicional (aprender fazendo) feita diretamente no pátio de atividades, beirava a improvisação, ficando na dependência da boa vontade dos mestres e oficiais. Esse quadro se apresentava em todas as ferrovias do Brasil e se distanciava bastante da elaboração técnica e científica.

Para Ciavatta (2007), tendo por base as exigências do sistema capitalista, a educação profissional modelou-se por uma visão que reduzia a formação ao treinamento para o trabalho simples ou especializado, para os trabalhadores e seus filhos. A

\footnotetext{
${ }^{8}$ Pedrosa (2014) destaca como exemplo as conferências "Missão do Serviço Nacional de Aprendizagem Industrial”; e "O passado e o futuro do Senai" (PEDROSA apud ZANATA, 1991), ambas proferidas em 1943 para os diretores regionais do SENAI em seminários nacionais da instituição.
} 
ideia de introdução do trabalho como princípio educativo na atividade escolar ou na formação de profissionais supunha recuperar para todos a dimensão do conhecimento científico-tecnológico da escola unitária e politécnica, introduzir nos currículos a crítica histórico-social do trabalho no sistema capitalista, os direitos do trabalho e o sentido das lutas históricas no trabalho.

Nessa perspectiva, Oliveira (2013), afirma que o ensino profissionalizante, desde a década de 1920, começava a ser pensado nos moldes a racionalização, discutido e implementado por vários intelectuais e empresários brasileiros que acreditavam que a racionalização do processo de ensino e de aprendizagem traria qualidade e agilidade à formação dos jovens, pois se caracterizava por elementos até então ausentes do aprendizado do ofício.

Com apoio e subsídio do governo paulista, outras empresas férreas criaram os Centros Ferroviários de Ensino e Seleção Profissional que se expandiram rapidamente pelo território paulista alcançando cidades, como: Jundiaí, Rio Claro, Campinas, Araraquara, Bebedouro, Bauru, Pindamonhangaba, São Paulo e Sorocaba. Ressalta-se a preocupação das escolas atenderem prioritariamente as necessidades de formação técnica e prática destinada aos operários das oficinas.

\section{A Expansão dos CFESP e a Formação dos Trabalhadores das Ferrovias nas Décadas de 1930 e} 1940

A expansão das estradas de ferro a partir da criação dos Centros Ferroviários de Educação e Seleção Profissional advém do plano estratégico para a criação de algumas cidades no território brasileiro, assim como a ascensão do desenvolvimento de regiões, haja vista a necessidade crescente da mão de obra disciplinada e qualificada. De acordo com Batista (2013, p. 173) destacaram-se [...] cidades do interior do Estado de São Paulo, Goiás, Mato Grosso, Minas Gerais e Rio de Janeiro, bem como para o desenvolvimento regional, como, por exemplo, a região de Rio Claro e Campinas (Estado de São Paulo) e a Região do Triângulo Mineiro (Minas Gerais).

Nesse intento, buscava-se a construção do domínio não só da técnica, mas também a compreensão de uma consciência política por parte dos trabalhadores na organização do trabalho. Nesse constructo, os Centros disseminavam a racionalização do trabalho a partir do Taylorismo com as séries metódicas advindo do projeto de engenheiros e educadores da Escola Politécnica.

A partir disso, observa-se a expansão dos Centros para a promoção não só da logística de produção e, por conseguinte, a economia, haja vista a promoção do desenvolvimento industrial no país. Sobre isso, Saviani (2007, p. 188) menciona que:

$\mathrm{Na}$ verdade, as ferrovias constituíram-se na base de um processo de urbanização e industrialização. Com efeito, em torno de cada estação desenvolvia-se um núcleo urbano e constituíam-se nas oficinas de manutenção que absorviam mão-de-obra imigrante para as tarefas mecânicas de manutenção, reparo e substituição de peças das locomotivas e vagões, emergindo o gérmen de atividades industriais.

Dessa forma, os CFESP refletem a construção da modernidade no país, da qual o Estado de São Paulo foi pioneira com a Estrada de Sorocabana (1931), servindo de modelo para disseminação em outras partes do Brasil a partir do ideário de formação profissional do trabalhador com base no tripé dos saberes da medicina, da engenharia e da educação. Descortinava-se uma "nova sociedade brasileira do mundo urbano-industrial, rearticulando eugenia, ensino e trabalho num todo homogêneo, normativo e disciplinador do universo social” (Tenca, 2006, p. 31).

Nesse projeto, o intelectual e engenheiro Roberto Mange foi diretor da Escola Mecânica anexa ao Liceu, da qual deu origem os Centros Ferroviários. Nesse contexto, tinha estreita relação com o instituto de Higiene de São Paulo, onde difundia os princípios da psicotécnica por meio dos métodos da seleção e formação profissional. Revelava-se as propostas de formar o "trabalhador ideal”, “comportado", “civilizado", “colaborador” (Segnini, 1986, p. 87). 
Desse modo, os Centros ferroviários possuíam uma organização alicerçado nos conhecimentos da psicologia experimental, onde se promovia a seleção dos aprendizes, os exames e seriação, a orientação vocacional e a organização de classes homogêneas. Nesse espaço, os alunos ao mesmo tempo que aprendiam o ofício, produziam peças das quais eram utilizadas nas próprias ferrovias. Em torno disso, Souza (2012, p. 62) assinala que:

A psicotécnica passou a prestar valoroso serviço à produção, pois, ao estudar e analisar o trabalho, ao ativar as características de cada operação", ela vai definindo aptidões e capacidades para que possam realizar bem suas funções. A psicotécnica classifica, pois aponta "o trabalhador, segundo a presença isolada ou combinada de certas características (inteligência, educação, conhecimentos técnicos, etc), em grau que satisfaça as características próprias do trabalho.

Assim, compreendia-se o ensino profissional pautado no adestramento e o controle do trabalho, sob a lógica racional. Portanto, buscava-se garimpar as aptidões para os saberes dos ofícios, onde os alunos aprendiam sob a orientações dos instrutores as ocupações a partir dos exercícios na ordem crescente no grau de dificuldade. Boschetti (2006, p. 54) descreve que:

Hierarquicamente, os ofícios consideravam três níveis de identificador profissional: mestres, oficiais e aprendizes. O mestre ocupava o mais alto grau da escala hierárquica da profissão. Era superior a seus oficiais e aprendizes e equivalente em prestígio aos demais mestres da mesma Corporação, característica comprovadora do sistema corporativo medieval: igualdade dentro de um escalonamento definido e claro, com possibilidade de mobilidade ascendente o quê permitiria ao aprendiz tornar-se oficial e este, ser mestre futuramente. $\mathrm{O}$ aprendizado se desenvolvia em quatro anos, findo os quais submetia-se às provas que deveriam demonstrar sua maturidade profissional para chegar aos postos hierárquicos acima do seu.

A ideia central na formação desenvolvida nos Centros era o aumento da produção, onde a organização consistia na racionalização pela 'divisão do trabalho' na oficina, cuja tarefa era desenvolvida em duração necessária a partir das turmas e disposição das máquinas, fornecendo assim eficiência ao sistema fabril.

Durante o período de 1934 a 1945, o CFESP promoveu um trabalho em consonância com as produções disseminadas pelo IDORT, constituindo-se como espaço de seleção e formação do trabalhador. Esse legado foi alicerce para o desenvolvimento do ensino industrial no SENAI. Nesse entorno, o engenheiro Roberto Mange foi primeiro diretor do CFESP, sendo também o primeiro diretor do SENAI.

O Centro ferroviário serviu de 'laboratório' para aprimorar os processos metódicos e racionais por meio do conhecimento partilhado nas experiências advindas das viagens na Europa, em particular na Alemanha, das quais foram realizadas por Roberto Mange. Com isso, observa-se o que tinha de mais moderno no ensino profissional mediante o modelo das estradas de ferro alemãs a partir da metodologia explorada, além dos programas, horários e regulamentos dos cursos ferroviários.

Com isso, o CFESP impulsionou a expansão destes centros em todo território brasileiro, tendo em vista que "em 1942, $83 \%$ do total da força de trabalho ferroviário do país, correspondente a $73 \%$ da extensão das vias férreas, estava sendo atendida pelo CFESP" (Cunha, 2000, p. 138). Em outros estados (do Ceará ao Rio Grande do Sul) o CFESP promoveu às ferrovias assistência técnica, por meio de publicações especiais, ações padronizadas, desenhos das séries metódicas de aprendizagem ou diretamente dos seus técnicos (Batista, 2009). A experiência do CFESP "extrapolou os limites das empresas ferroviárias para tornar-se um modelo de organização, entrando na pauta de todas as discussões sobre o ensino profissional ocorridas no final da década de 30" (Senai, 1991, p. 111).

Com a extinção do CFESP através do Decreto n. 18.087, de 20 de abril de 1948, é dada a continuidade dessa experiência nas escolas profissionais, à exemplo do SENAI, onde se evidenciassem ações padronizadas para o 
desenvolvimento da aprendizagem sob o controle e vigilância do instrutor. Compreende-se o CFESP enquanto tradição de luta e resistência, bem como o modelo de práticas para a formação do trabalhador, do qual impulsionou o ensino industrial no Brasil.

\section{Considerações Finais}

No contexto geral da formação para o trabalho entre as décadas de 1930 e 1940, considerando-se as necessidades de qualificação de trabalhadores para as ferrovias, evidenciou-se a importância do professor Roberto Mange, tanto no aspecto teórico quanto no prático. No aspecto prático, como apresentamos nesse artigo, criou e organizou métodos, cursos, escolas, dentre elas o Centro de Formação e Seleção Profissional, algo muito relevante para o atendimento das demandas do setor ferroviário. Já no aspecto teórico, como um intelectual articulado e metódico, divulgou suas ideias nos textos que escreveu, à exemplo dos disseminados pelo IDORT, pondo em prática parte dessas ideias nas escolas que fundou e em tantas outras ações.

Mange usou referências internacionais procurando implementar muitas delas tanto nos centros de formação e seleção profissional das estradas de ferro como nas demais escolas de ensino técnico industrial. Nesse aspecto o CFESP reveste-se de uma singularidade ímpar considerando-se a sua contribuição para o aprimoramento dos processos metódicos e racionais e do uso da Psicologia e Psicotécnica que seriam utilizados posteriormente nas escolas de formação técnica industrial por todo o país, inclusive nas Escolas do SENAI.

Os centros ferroviários espalharam-se pelo país exercendo um protagonismo no contexto da formação profissional, indo além da preparação de mão de obra para as ferrovias, tornando-se modelo de organização para o ensino técnico nas décadas de 1930 e 1940.

\section{Referências}

Batista, E. L (2013). Trabalho e educação profissional nas décadas de 1930 e 1940 no Brasil: análise do pensamento e das ações da burguesia industrial a partir do IDORT. Revista HISTEDBR. 14(59), 341-341. 10.20396/rho.v14i59.8640369. https://periodicos.sbu.unicamp.br/ojs/index.php/histedbr/ article/view/8640369.

Batista, E. L. (2015). Escola de Formação Ferroviária Sorocabana. Pedagogia em Foco, Iturama (MG). 10(4), 90-103.

Batista, M. I. (2009). O Estado Novo e as novas perspectivas no processo educacional brasileiro: os reflexos na expansão do ensino ferroviário (1937-1945), 2009.

Batista, S. S. S., \& Carvalho, M. L. M. (2015). Estudo sobre os cursos ferroviários nos anos de 1940 a 1960 a partir de revistas ferroviárias. Educação em Revista. 31(03), 143-167 Belo Horizonte Julho-Setembro 2015.

Boschetti, V. R. (2006). O curso ferroviário da Estrada de Ferro Sorocabana. Revista Histedbr. Campinas, n. 23, p. 46-58.

Ciavatta, M. (2007. Memória e Temporalidades do Trabalho e da Educação: Lamparina Editora, FAPERJ.

Cunha, L. A. (2000). O ensino profissional na irradiação do industrialismo. São Paulo: Unesp; Brasília: Flacso.

Fonseca, C. S. (1961). História do Ensino Industrial no Brasil. (volume 1). Rio de Janeiro.

Fonseca, C. S. (1962). História do Ensino Industrial no Brasil. (volume 2). Rio de Janeiro.

Miranda, W. A. (2019). Vida e Obra de Roberto Mange. Boletim Academia Paulista de Psicologia. 39(97) São Paulo.

Oliveira, M. (2013). O Curso de Ferroviários da Estrada de Ferro Sorocabana (1931-1950). Programa de Pós-Graduação em Educação da Universidade de Sorocaba. http://periodicos.jf.ifsudestemg.edu.br/multiverso/article/view/348

Pedrosa, J. G., \& Santos, O. G. (2014). Agentes do ensino industrial no brasil (1920-30-40) e suas referências internacionais: europeísmo e americanismo. Cadernos de História da Educação, 13(1). http://www.seer.ufu.br/index.php/che/article/view/28181

Saviani, D. (2007). História das ideias pedagógicas no Brasil. Campinas: Autores Associados.

Schwartzman, S., Bomeny, H. M. B., \& Costa, V. M. R. (2000). Tempos de Capanema. São Paulo; Rio de Janeiro: Paz e Terra; Editora da Fundação Getúlio Vargas.

Segnini, L. R. P. (1986). Taylorismo: Uma análise crítica. In: Bruno, L. Organização, trabalho e tecnologia. São Paulo: Atlas. 
Research, Society and Development, v. 10, n. 13, e249101321383, 2021

(CC BY 4.0) | ISSN 2525-3409 | DOI: http://dx.doi.org/10.33448/rsd-v10i13.21383

Senai. (1991). De Homens e Máquinas: Roberto Mange e a formação profissional. São Paulo, Senai.

Seveino, A. J. (2016). Metodologia do Trabalho Científico - (24 a . ed.) rev. e atual. - São Paulo: Cortez.

Souza, L. M. (2012). Entre o ideal e o real: a construção do pensamento empresarial uberlandense e seus projetos educacionais para a formação dos trabalhadores. Tese (Doutorado em Educação), Universidade Federal de Uberlândia (UFU), Minas Gerais.

Tenca, A. (2006). Senhores dos trilhos: racionalização, trabalho e tempo livre nas narrativas de ex-alunos do curso de ferroviários da antiga paulista. São Paulo: Unesp.

Weinstein, B. (2000). (Re) formação da classe trabalhadora no Brasil, 1920-1964. São Paulo: Cortez Editora.

Zanetti, A. (2001). A engenharia pedagógica: taylorismo e racionalização no Pensamento de Roberto Mange. Tese de doutorado - Universidade Estadual de Campinas. Instituto de Filosofia e Ciências Humanas. Capinas/SP. 